\title{
Readout temperature effect on the response of the genipin gel dosimeter
}

\author{
F. Bahrami ${ }^{1}$, S.M.M. Abtahi ${ }^{*}$, D. Sardari ${ }^{1}$, M. Bakhshandeh3 \\ ${ }^{1}$ Department of Medical Radiation Engineering, Science and Research Branch, Islamic Azad University, Tehran, \\ Iran \\ 2Physics Department, Imam Khomeini International University, Qazvin, Iran \\ ${ }^{3}$ Department of Radiology Technology, Allied Medical Faculty, Shahid Beheshti University of Medical Sciences, \\ Tehran, Iran
}

\section{- Original article}

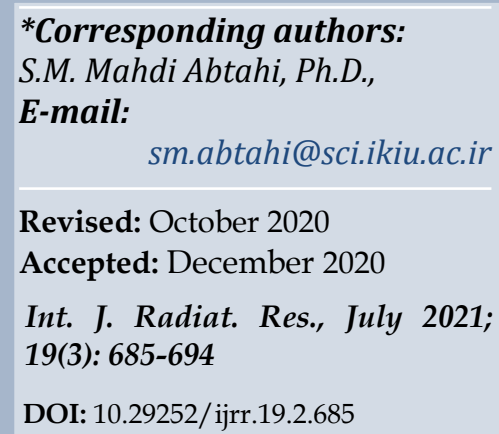

Revised: October 2020

Accepted: December 2020

Int. J. Radiat. Res., July 2021; 19(3): 685-694

DOI: $10.29252 /$ ijrr.19.2.685

\begin{abstract}
Background: The present study aimed to investigate the dependence of the response of the genipin gel dosimeter on readout temperatures. Materials and Methods: To this aim, after the gel preparation, they were exposed by a Varian Medical Linac accelerator with a dose range of 0-10 Gy. Then the irradiated samples were readout by a spectrophotometer device at $5^{\circ} \mathrm{C}, 10^{\circ} \mathrm{C}$, $15^{\circ} \mathrm{C}$ and $20^{\circ} \mathrm{C}$ temperatures. Results: Results revealed that the response of the genipin gel dosimeter is extremely temperature-dependent. For the mentioned readout temperatures, the maximum dose sensitivity was related to $10^{\circ} \mathrm{C}$ and its value was $35 \times 10^{-3} \mathrm{~cm}^{-1} \mathrm{~Gy}^{-1}$. Investigation of the AUS (area under spectra) depicted that the maximum dose sensitivity was also related to $10^{\circ} \mathrm{C}$. Furthermore, investigation of the dose resolution of this gel dosimeter showed that the minimum detectable dose was related to $10^{\circ} \mathrm{C}$, and its amount was $0.24 \mathrm{~Gy}$. Conclusion: The results confirmed a noticeable change in the response of the genipin gel dosimeter due to variations of the readout temperature. It can be concluded that the response sensitivity of this radiochromic gel dosimeter increased by readout temperature decreasing.
\end{abstract}

Keywords: Genipin gel dosimeter, dose sensitivity, readout temperature, dose resolution.

\section{INTRODUCTION}

Gel dosimeters consist of chemicals sensitive to radiation, which, upon exposure, change as a function of the absorbed radiation dose $(1,2)$. These changes make clinical utilization of gel dosimeters in radiotherapy applications $(3,4)$. Some kinds of gel dosimeters are specially effective for organ dose estimation in different radiation therapy methods $(5,6)$. One group of gel dosimeters, known as radiochromic gel dosimeters, change their color due to irradiation, and this colour change leads to variation in optical density and absorbance of the gel (7). Such gel dosimeters have remarkable features such as three-dimensional measurement of spatial dose distribution, 3D quality assurance in radiotherapy technique, and tissue equivalency. These advantages have made possible major applications of gel dosimeters for dose verification of the Gamma Knife technique (8) and other radiotherapy techniques such as Stereotactic radiosurgery (9). Among these gel dosimeters, the genipin-gel dosimeter has outstanding behaviour. The genipin is a fruit extracted from gardenia jasminoides ellis (10), and its molecular formula is $\mathrm{C}_{11} \mathrm{H}_{14} \mathrm{O}_{5}$. It can cross-link with gelatin amino acids and form blue pigments (11). Jordan has shown that (12) the genipin-gel dosimeter is a radiochromic and bleaches upon exposure by the photon beam. This color change can be measured using optical computed tomography (OCT) or a spectrophotometer. Jordan concluded that this 
hydrogel is zero-diffusion. This property is the unique feature of the genipin gel dosimeter. In any gel dosimeter, the problem of diffusion causes some changes for clinical applications (13-15). Water equivalency of the genipin gel dosimeter for electron beams and X-ray was investigated by Gorjiara et al. (16). Subsequently, in another study (17), they calculated the radiological properties of the genipin gel dosimeter, such as effective atomic number, mass density, photoelectric cross-section. It was found that for electron beam and X-ray dosimetry, this gel dosimeter can be considered as a water equivalent dosimeter. In research by Jarrah et al. (18) effect of adding inorganic salts on the dose sensitivity and thermal stability of the genipin gel dosimeter was checked.

Davies et al. ${ }^{19)}$ presented a new formulation for the genipin-gelatin gel dosimeter as follows: by adding the sulfuric acid, the gel dose sensitivity was enhanced enough for radiotherapy dosimetry quality assurance. Also, they have illustrated that darker gels have higher dose sensitivity and lower uncertainty. In another study by Davies et al. (20) by conducting a series of experiments with different amounts and concentrations of constituent materials such as genipin, gelatin, and sulfuric acid, and the effective parameters in the gel preparation process (proper temperature for adding material at any stage, blending time, etc.) were investigated. They presented the most appropriate combination and methods for preparing this radiochromic gel dosimeter. Dependence of this gel on dose rate, irradiation, and readout temperature was also studied.

One of the problems of the genipin gel dosimeter compared with other gel dosimeters is its low sensitivity, especially in lower doses. As shown by De Deene et al. (21), as the scanning temperature of samples increases, the dose sensitivity of PAG, nPAG, and nMAG gel dosimeters decreases. The present study investigates the response sensitivity and dose resolution of the genipin-gel dosimeter at different readout temperatures. Furthermore, in this research, a new parameter was introduced to read out the genipin gel dosimeter. The idea for introducing the new parameter for reading out was based on research carried out by Abtahi et al. (22).

\section{MATERIALS AND METHODS}

\section{Genipin gel preparation}

In the current study, the genipin-gel dosimeter was prepared under the environmental condition. The method applied by Davies et al. (20) was used to prepare this gel dosimeter. The most suitable formulation was suggested to be made from $50 \mu \mathrm{M}$ genipin, $4 \%$ $\mathrm{w} / \mathrm{w}$ gelatin, and $100 \mathrm{mM}$ sulphuric acid. At first, in a sealed flask (to avoid any extra irradiation to gel solution during preparation), pure water (High-pressure liquid chromatography (HPLC) grade, obtained from Direct-Q 3 UV water purification system, Millipore, France) with weight percent of $96 \mathrm{w} / \mathrm{w} \%$ was added. Then gelatin (Porcine Skin, Type A, 300 Bloom, Sigma Aldrich, USA) was added to water, and the gelatin-water mixture was left at room temperature for 10 minutes so that the gelatin was swollen. The total flask volume was put in a water bath, and the water bath was placed on a heater-stirrer plate (IKA, RH basic KT/C, Germany). Then the water bath temperature was increased to $45^{\circ} \mathrm{C}$. Afterwards, the solution was stirred with a magnet simultaneously. This stage was continued for $2 \mathrm{~h}$ until the gelatin was dissolved completely in water to obtain a clear solution.

At the next step, the genipin (Merck Ltd., Germany) was added to the solution, and the temperature was increased to $70^{\circ} \mathrm{C}$. The solution was left to be stirred gradually for $5 \mathrm{~h}$ to avoid bubble formation. Then, sulfuric acid was added to the solution, and it was stirred for $10 \mathrm{~min}$. Finally, a dark blue gel was achieved. Afterwards, the solution was poured in $1 \mathrm{~cm}$ spectrophotometer cuvettes $\left(1 \times 1 \times 4.5 \mathrm{~cm}^{3}\right.$, Polystyrene, Guangzho JET Bio-filtration products, Ltd, China) in a dark room to keep the gel dosimeter solutions away from unwanted exposure. Then the top of the cuvettes was covered with parafilm, and all cuvettes were shielded by aluminium foil to avoid any light penetration. Then, the cuvettes were placed in a 
flask and stored in a refrigerator at $4^{\circ} \mathrm{C}$ for $24 \mathrm{~h}$ before irradiation.

\section{Irradiation}

A Varian linear accelerator (Clinac 600c, USA) was used to expose the produced gel dosimeters by photons. The cuvettes were placed under $3 \mathrm{~cm}$ Perspex, and $2 \mathrm{~cm}$ Perspex was put beneath the cuvettes to ensure photon scattering. For irradiation, a square field size of $12 \times 12 \mathrm{~cm}^{2}$, a gantry rotation of $0^{0}$, a source to surface distance (SSD) of $96.5 \mathrm{~cm}$, an energy of $6 \mathrm{MV}$, and a dose rate of $200 \mathrm{cGy} / \mathrm{min}$ were used. Doses of 2, 4, 6, 8, and $10 \mathrm{~Gy}$ in $3.5 \mathrm{~cm}$ depth of vials were delivered. Two samples, as un-irradiated (blank) samples, were not exposed and stored. The irradiation room temperature was $(19 \pm 0.5)^{\circ} \mathrm{C}$. After exposure, cuvettes were shielded quickly by aluminium foil to prevent any unwanted exposure by environmental lights. The samples were backed on the flask to store before readout.

\section{Readout}

Samples were scanned by a spectrophotometer device (M350, Double beam UV-Visible spectrophotometer, England), immediately after irradiation. In the present study, 5, 10, 15, and 20 centigrade temperatures, were applied during the reading process. The temperature of the water bath was measured using a thermometer. Then samples were placed in the water bath to be equilibrated with the intended temperature for $35 \mathrm{~min}$ before scanning. Measurements of samples' absorption spectrum were carried out in a dark room. At each temperature, first, the blank samples were read, and its spectrums were subtracted from irradiated samples. The samples were measured for 400-800 $\mathrm{nm}$ wavelengths.

\section{AUS, a new parameter for reading out genipin gel dosimeter}

one of the parameters used for gel samples readout is the area under the absorbance spectra of exposed samples. It is obtained by numerical computation of the following integral (trapezoidal method) equation 1, (22):

(AUS) $=\int_{\lambda_{1}}^{\lambda_{2}}$ absorbance $(\lambda) \mathrm{d} \lambda$
In the above equation $\lambda_{1}$ is the first scanned absorption wavelength, and $\lambda_{1}$ is the final one. This parameter shows the turbidity of the gel according to different wavelengths. One of the remarkable features of the above parameter is increased dose sensitivity. The shape of the collected spectra was continuous and started from low absorbance and reached a maximum point at about $601 \mathrm{~nm}$ (related to genipin peak) and then decreased slowly.

By plotting linear fitting charts for absorbance peak or AUS at different doses, line slope in every readout temperature could be calculated. This slope is related to the dose sensitivity of gel (19). The goodness of fit can be evaluated using R-square and adjusted R-square. Interested readers are referred to reference (23) for more details about the goodness of fit parameters. As the R-square and adjusted R-square values approach one, the linearity of the response gets better. RMSE (root-meansquare error) parameter is usually non-negative and used to measure the differences between the values of samples. Also, this parameter represents the differences between predicted and observed values ${ }^{(23)}$.

\section{Dose resolution}

The concept of dose resolution was reported by Baldock et al. (24). The minimal value for discrimination of two detectable absorbed doses with a certain level of confidence $p$ is named dose resolution $\left(D_{\Delta}^{P}\right)$ that it is introduced by the equation 2 (25):

$D_{\Delta}^{P}=K_{P} \sqrt{2} \frac{\sigma_{R}}{\alpha}$

In upper equation $K_{p}$ is coverage factor, $\sigma_{R}$ is the standard deviation in $\mathrm{R}$, and $\alpha$ is the sensitivity value of the gel dosimeter. Baldock et al. (24) reported coverage factor values for different levels of confidence. For example, $\mathrm{K}_{\mathrm{p}}$ of $1 / \sqrt{2}, 1,1.96$ are related to $52 \%, 68 \%$ and $95 \%$ respectively. In equation 2 , as the dose reaches zero, $D_{\Delta}^{P}$ shows the minimal detectable dose (MDD).

\section{Statistical analysis}

Statistical analysis in the current study was 
performed using SPSS software (IBM SPSS@ Statistics) which the Tukey, ANOVA and 2-tailed tests. Tukey test compares all possible pairs of means to understand the statistical significance. ANOVA test is used to determine any statistically significant differences between means of three or more independent group. The 2 -tailed test is a way of computing the statistical significance of a parameter inferred from a data set (23).

\section{RESULTS}

\section{Dose-absorbance response}

The wavelengths at which the maximum absorbance of each absorbed dose occurred are reported in table 1 . As observed for each dose, the wavelength of the maximum absorbance shows a peak shift in the interval of 599-603 nm. The mean wavelength amounts and its related standard deviation is almost $601 \pm 1.5 \mathrm{~nm}$. Figure 1 shows the results obtained from different doses at various readout temperatures. As demonstrated in this figure, the amount of maximum absorbance for investigated readout temperatures is related to $5^{\circ} \mathrm{C}$. Furthermore, it could be seen that by readout temperature increasing the absorbance amount decrease. At $15^{\circ} \mathrm{C}$ and $20^{\circ} \mathrm{C}$, the spectra related to different doses overlapped, representing a decrease in gel dosimeter sensitivity at higher readout temperatures.

Figure 2 demonstrates linear fits to the absorbance peak as a function of the absorbed dose. Relations between the absorbance peak and the absorbed dose at the scanning temperature of $5^{\circ} \mathrm{C}, 10^{\circ} \mathrm{C}, 15^{\circ} \mathrm{C}$ and $20^{\circ} \mathrm{C}$ can be described by equations 3 through 6 , respectively. The goodnesses of linear fits at different scanning temperature are shown in table 2 .

Table 1. Maximum wavelength amounts related to different doses and temperatures.

\begin{tabular}{|c|c|c|c|c|c|}
\hline & \multicolumn{5}{|c|}{ Dose (Gy) } \\
\hline Temperature ( $\left.{ }^{\circ} \mathbf{C}\right)$ & $\mathbf{2 ~ G y}$ & $\mathbf{4 ~ G y}$ & $\mathbf{6 ~ G y}$ & $\mathbf{8 ~ G y}$ & $\mathbf{1 0 ~ G y}$ \\
\hline 5 & 602 & 599 & 601 & 599 & 602 \\
\hline 10 & 599 & 603 & 602 & 602 & 602 \\
\hline 15 & 599 & 600 & 602 & 599 & 600 \\
\hline 20 & 599 & 599 & 599 & 599 & 599 \\
\hline
\end{tabular}

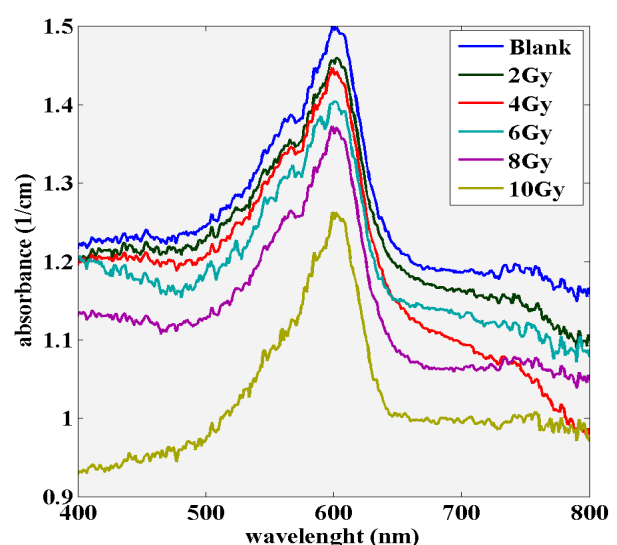

(A)

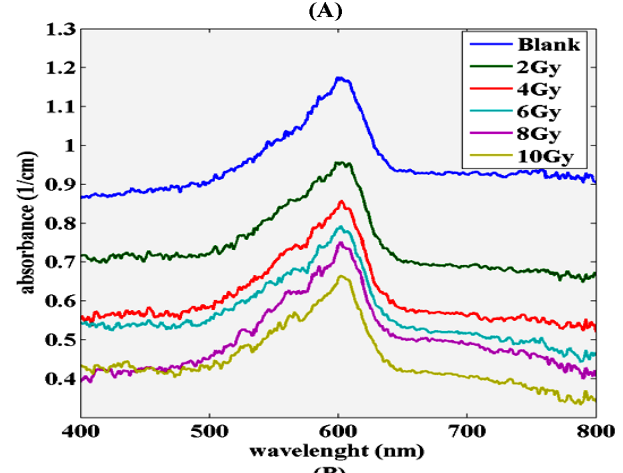

(B)

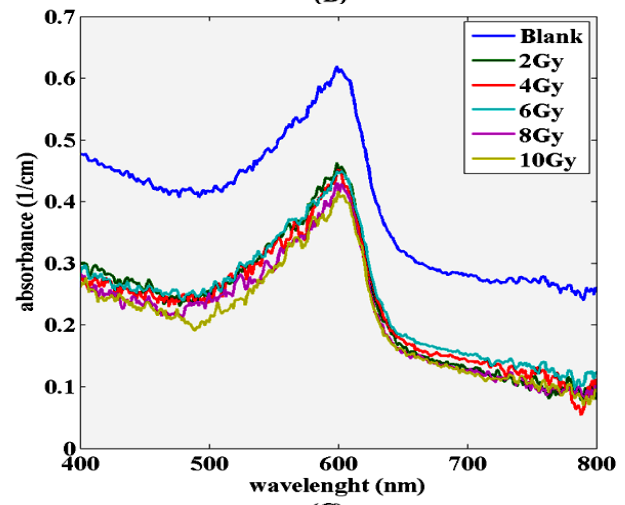

(C)

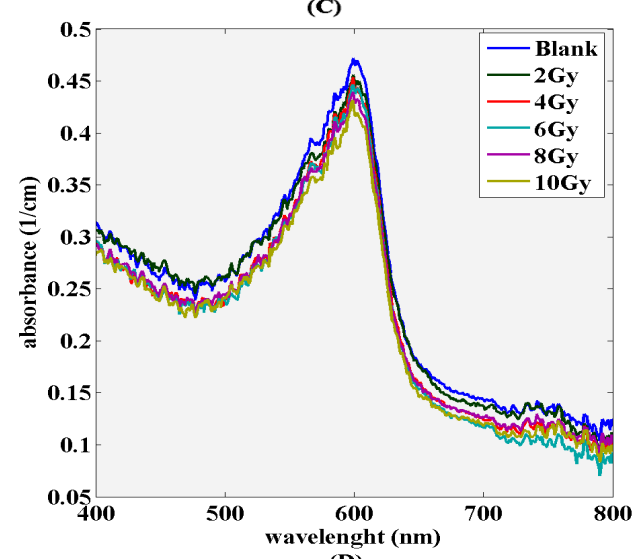

(D)

Figure 1. Absorbance spectra of irradiated genipin gel samples related to different doses at different readout temperatures: (A) $5^{\circ} \mathrm{C}$; (B) $10^{\circ} \mathrm{C}$; (C) $15^{\circ} \mathrm{C}$; (D) $20^{\circ} \mathrm{C}$.

Int. J. Radiat. Res., Vol. 19 No. 3, July 2021 

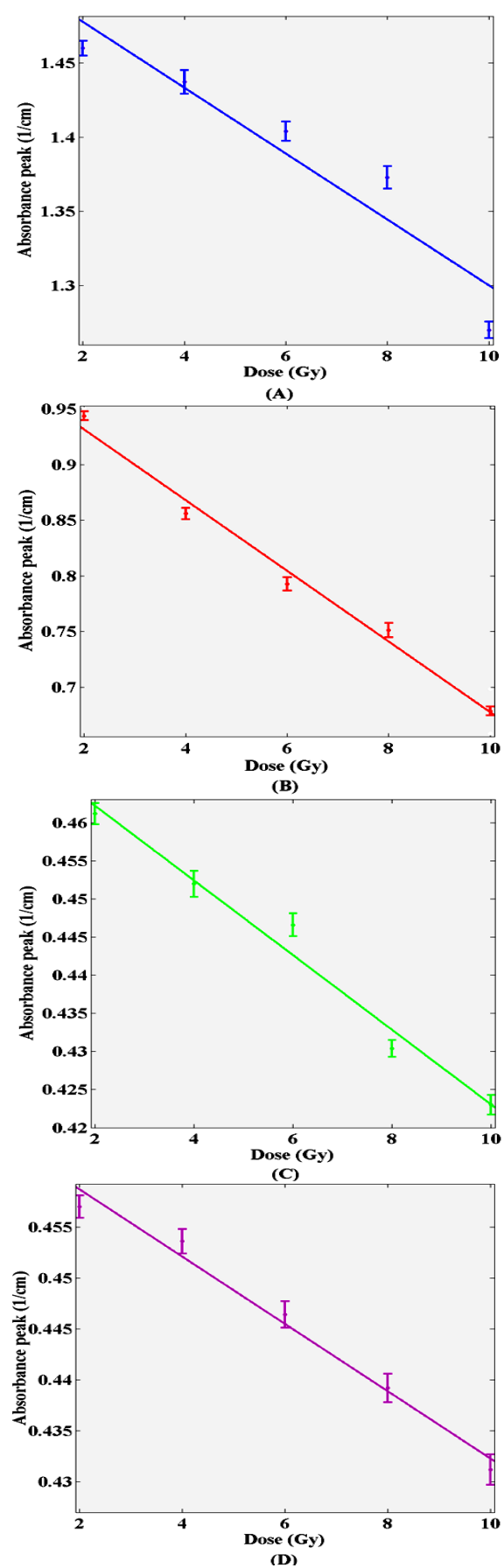

Figure 2. Linear fitting curves that show the linearity response of genipin gel dosimeter at readout temperature of (A) $5^{\circ} \mathrm{C}$; (B) $10^{\circ} \mathrm{C}$; (C) $15^{\circ} \mathrm{C}$; (D) $20^{\circ} \mathrm{C}$.

Table 2. The goodness of linear fit for absorbance response of genipin gel dosimeter at various readout temperatures.

\begin{tabular}{|l|l|l|l|}
\hline Temperature $\left({ }^{\circ} \mathrm{C}\right)$ & R-Square & Adjusted R-Square & RMSE \\
\hline
\end{tabular}

\begin{tabular}{|c|c|c|c|}
\hline 5 & 0.93 & 0.921 & 0.0202 \\
\hline 10 & 0.982 & 0.97 & 0.0174 \\
\hline 15 & 0.974 & 0.961 & 0.0019 \\
\hline 20 & 0.972 & 0.959 & 0.0016 \\
\hline
\end{tabular}

Int. J. Radiat. Res., Vol. 19 No. 3, July 2021
Absorbance $>(-0.0024 \times$ Dose $)+1.514$

Absorbance $>(-0.0035 \times$ Dose $)+1.013$

Absorbance $>(-0.0061 \times$ Dose $)+0.446$

Absorbance $>(-0.0057 \times$ Dose $)+0.463$

Results showed higher sensitivities for the readout temperature of $10^{\circ} \mathrm{C}$ compared with other investigated readout temperatures. For the gel dosimeter fabricated in the current study, the dose sensitivity was increased by $49 \%$ when the readout temperature changed in a range of $5^{\circ} \mathrm{C}$ to $10^{\circ} \mathrm{C}$. However, the sensitivity variations of $82.6 \%$ and $5 \%$ were observed for readout temperature ranges of $10^{\circ} \mathrm{C}-15^{\circ} \mathrm{C}$ and $15^{\circ} \mathrm{C}-$ $20^{\circ} \mathrm{C}$, respectively. By statistical analysis, it was cleared that there is a significant difference $(p<0.05)$ between the dose sensitivity of genipin gel dosimeter at $5^{\circ} \mathrm{C}$ and $10^{\circ} \mathrm{C}, 5^{\circ} \mathrm{C}$ and $15^{\circ} \mathrm{C}, 5^{\circ} \mathrm{C}$ and $20^{\circ} \mathrm{C}, 10^{\circ} \mathrm{C}$ and $15^{\circ} \mathrm{C}, 10^{\circ} \mathrm{C}$ and $20^{\circ} \mathrm{C}$ readout temperatures. Only between $15^{\circ} \mathrm{C}$ and $20^{\circ} \mathrm{C}$ readout temperatures there is no significant difference ( $>0.05)$.

By considering the $\mathrm{R}^{2}$ parameter as a criterion for linearity of the gel dosimeter response, by increasing the readout temperature from $5^{\circ} \mathrm{C}$ to $10^{\circ} \mathrm{C}, 8 \%$ increase in linearity was observed. However, the readout temperature increasing from $10^{\circ} \mathrm{C}$ to $15^{\circ} \mathrm{C}$ and from $15^{\circ} \mathrm{C}$ to $20^{\circ} \mathrm{C}$, caused linearity reductions of $1 \%$, and $2 \%$, respectively. At room temperature, the R-square $\left(R^{2}\right)$ value of genipin gel dosimeter is $R^{2}=0.972$.

\section{AUS response}

The results obtained from the AUS calculation are shown in table 3 . It is inferred that in each absorbed dose, AUS sensitivity decreases as the readout temperature increases. At each readout temperature, decreasing the X-ray dose leads to an increase in AUS sensitivity. This case shows more UV (ultraviolet) light absorption and increased absorption levels in samples. Due to variation in irradiation dose and readout temperature, the related wavelength was changed, and each colour has its specific wavelength. Through calculating the area under absorbance spectra, variation in absorbance level could be assessed. Figure 3 shows AUS values at $5^{\circ} \mathrm{C}, 10^{\circ} \mathrm{C}, 15^{\circ} \mathrm{C}$ and $20^{\circ} \mathrm{C}$ readout temperatures. Besides, equations 7 through 10 
depicted the relation between AUS and absorbed dose at $5^{\circ} \mathrm{C}, 10^{\circ} \mathrm{C}, 15^{\circ} \mathrm{C}$ and $20^{\circ} \mathrm{C}$ readout temperatures, respectively. Results show that at $15^{\circ} \mathrm{C}$ and $20^{\circ} \mathrm{C}$ readout temperatures, the difference between AUS sensitivities were not significant. In table 3 , the goodness of linear fit for mentioned readout temperatures is depicted. Results showed that AUS linearity (table 3 ) is the best for $10^{\circ} \mathrm{C}$ readout temperature $\left(\mathrm{R}^{2}=0.978\right)$.

AUS value $>(-9.26 \times$ Dose $)+513.3$

AUS value $>(-13.99 \times$ Dose $)+303$

AUS value $>(-1.24 \times$ Dose $)+99.1$

AUS value $>(-0.99 \times$ Dose $)+91.7$

AUS calculations have shown that the maximum AUS sensitivity was related to $10^{\circ} \mathrm{C}$ scanning temperature. For this gel dosimeter, at the readout temperature range of $5^{\circ} \mathrm{C}$ to $10^{\circ} \mathrm{C}$, AUS sensitivity amount has increased by $51 \%$. In the scanning temperature ranges of $10^{\circ} \mathrm{C}-15^{\circ} \mathrm{C}$ and $15^{\circ} \mathrm{C}-20^{\circ} \mathrm{C}$, AUS has decreased by $91 \%$ and $27 \%$, respectively. With statistical analysis, it is revealed that the difference between the AUS sensitivity of gel dosimeters at $5^{\circ} \mathrm{C}$ and $10^{\circ} \mathrm{C}, 5^{\circ} \mathrm{C}$ and $10^{\circ} \mathrm{C}, 5^{\circ} \mathrm{C}$ and $20^{\circ} \mathrm{C}, 10^{\circ} \mathrm{C}$ and $15^{\circ} \mathrm{C}, 10^{\circ} \mathrm{C}$ and $20^{\circ} \mathrm{C}, 15^{\circ} \mathrm{C}$ and $20^{\circ} \mathrm{C}$ readout temperatures are significant $(\mathrm{p}<0.05)$. However, at $5^{\circ} \mathrm{C}, 10^{\circ} \mathrm{C}, 15^{\circ} \mathrm{C}$ and $20^{\circ} \mathrm{C}$ readout temperatures, AUS increases the dose sensitivity of the genipin gel dosimeter by factors of $399.71,394.38,204.28$, and 157.34 times, respectively.

By increasing the readout temperature from $5^{\circ} \mathrm{C}$ to $10^{\circ} \mathrm{C}$, a $7 \%$ increase in the $\mathrm{R}^{2}$ parameter was observed. However, by increasing the readout temperature from $10^{\circ} \mathrm{C}$ to $15^{\circ} \mathrm{C}$ and $15^{\circ} \mathrm{C}$ to $20^{\circ} \mathrm{C}, \mathrm{R}^{2}$ reduced by factors of $2 \%$ and $3 \%$, respectively.

\section{Dose resolution}

Dose resolution was calculated for the genipin-gelatin gel dosimeter for different readout temperatures. As shown in figure 4, the dose resolution for this gel dosimeter varies between 1.003 and $0.317 \mathrm{~Gy}$ in the 2-10 Gy dose range. Also, the MDD values of this gel for $5^{\circ} \mathrm{C}$ $10^{\circ} \mathrm{C}, 15^{\circ} \mathrm{C}$ and $20^{\circ} \mathrm{C}$ readout temperatures were 0.59 Gy, 0.238 Gy, 0.32 Gy, and 0.436 Gy, respectively.
Table 3. The goodness of linear fit for AUS* response of genipin gel dosimeter at various readout temperatures.

\begin{tabular}{|c|c|c|c|}
\hline Temperature $\left({ }^{\circ} \mathbf{C}\right)$ & R-Square & Adjusted R-Square & RMSE \\
\hline 5 & 0.966 & 0.951 & 6.089 \\
\hline 10 & 0.978 & 0.963 & 5.876 \\
\hline 15 & 0.973 & 0.961 & 0.859 \\
\hline 20 & 0.974 & 0.962 & 0.3508 \\
\hline
\end{tabular}

*Area Under Spectra
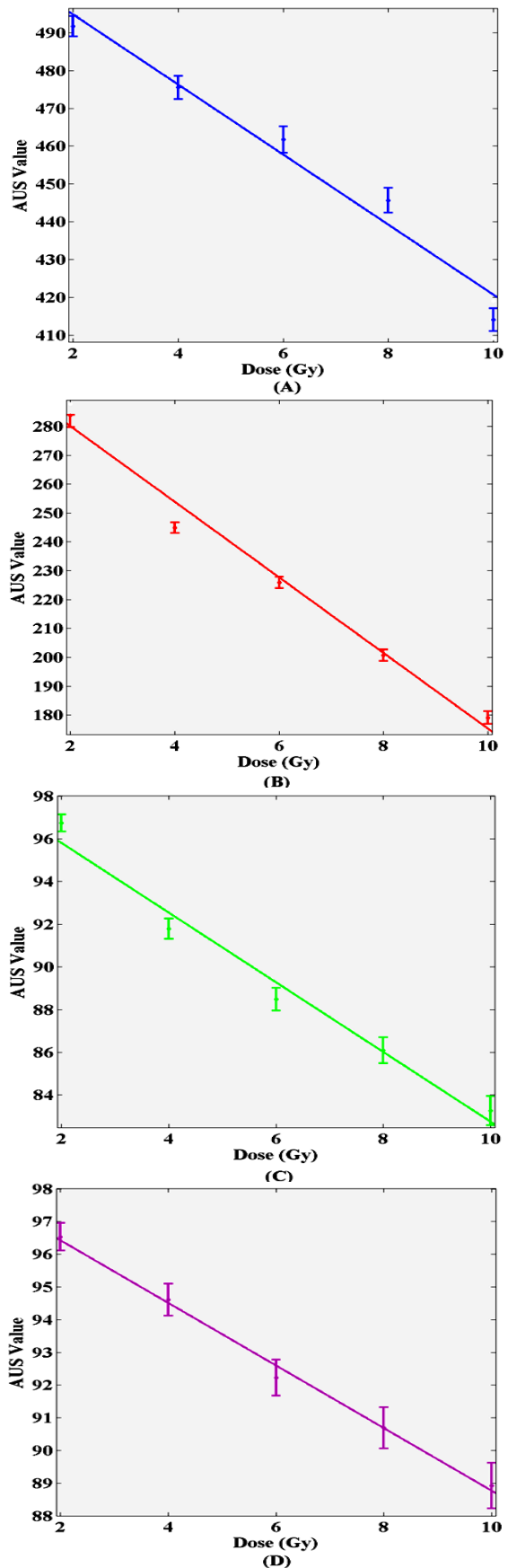

Figure 3. Linear fitting curves that show the AUS linearity of genipin gel dosimeter at readout temperatures of (A) $5^{\circ} \mathrm{C}$; (B) $10^{\circ} \mathrm{C}$; (C) $15^{\circ} \mathrm{C}$; (D) $20^{\circ} \mathrm{C}$.

Int. J. Radiat. Res., Vol. 19 No. 3, July 2021 


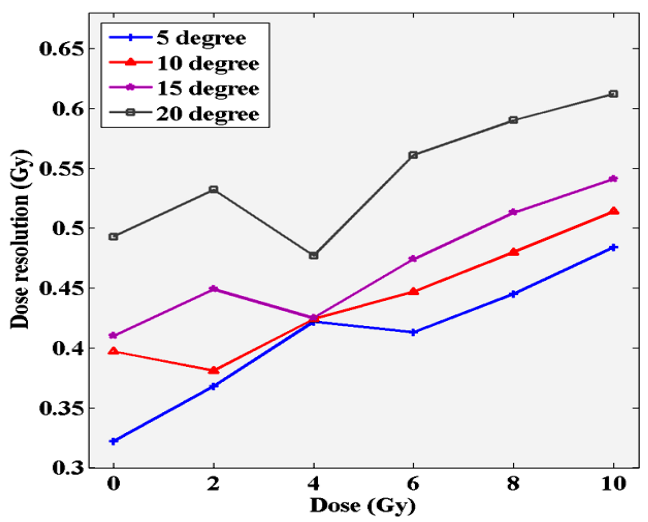

Figure 4. Genipin-gelatin dose resolution for different readout temperatures.

From the obtained results, it can be concluded that the best dose resolution and MDD (minimum detectable dose) for investigated readout temperatures was related to $10^{\circ} \mathrm{C}$ and $15^{\circ} \mathrm{C}$ readout temperatures, respectively.

\section{DISCUSSION}

In another study by Davies et al. (19), by increasing the readout temperature from $15^{\circ} \mathrm{C}$ to $20^{\circ} \mathrm{C}$, the sensitivity was decreased by a factor of $2 \%$. However, they claimed that this decrease was not significant. The sensitivity values obtained in the present study (from $15^{\circ} \mathrm{C}$ to $20^{\circ} \mathrm{C}$ readout temperatures) are near to those obtained in their study but not the same. This could be related to different reasons, such as various methods utilized for reading out the samples, different reading devices, different environmental conditions, etc. De Deene etal. (21) investigated PAG, nMAG and nPAG gel dosimeters. They reported, for different readout temperature increasings of $5^{\circ} \mathrm{C}$ to $10^{\circ} \mathrm{C}, 10^{\circ} \mathrm{C}$ to $15^{\circ} \mathrm{C}$, and $15^{\circ} \mathrm{C}$ to $20^{\circ} \mathrm{C}$, for PAG gel dosimeter, the dose sensitivity was decreased by $18 \%$, $13 \%$, and $35 \%$, respectively. Furthermore, they showed for the same readout temperature increasings, for the nMAG gel dosimeter, the sensitivity was decreased by factors of $12 \%$, $12 \%$, and $15 \%$, respectively. Also, for nPAG gel dosimeter and the same readout temperature ranges, the decreases of $19 \%, 12 \%$, and $23 \%$, respectively, were observed. It seems that for most of the gel dosimeters, by decreasing readout temperature, the dose sensitivity increases. Abtahi et al. studied about PAGATUG gel dosimeter (22). They showed that for the PAGATUG gel dosimeter, the sensitivity at a scanning temperature of $10^{\circ} \mathrm{C}$ is $15 \%$ more than that at $20^{\circ} \mathrm{C}$. At $10^{\circ} \mathrm{C}-20^{\circ} \mathrm{C}$ scanning temperatures, the PAGATUG gel dosimeter showed severe dependence on temperature, and this dependence can lead to remarkable reading errors. Although at temperatures higher than $20^{\circ} \mathrm{C}$, the temperature dependence was slight for their investigated gel dosimeter. Pavoni and Baffa (27) investigated the MAGIC-f gel dosimeter. They have shown that by increasing scan temperature, the dose sensitivity of MAGIC and MAGIC-f gel dosimeters was decreased. However, this reduction is more remarkable for the MAGIC-f gel dosimeter. Senden et al. (28) studied about Nipam/BIS, DAAM/BIS, and PAGAT gel dosimeters. They showed that dose-response and dose sensitivity of the mentioned gel dosimeters depend on the scanning temperature. In their research, three gels were scanned at $22^{\circ} \mathrm{C}$ and $27^{\circ} \mathrm{C}$. Their results have shown that temperature change led to a negligible variation in the response of the PAGAT and the DAAM/BIS gel dosimeters, but for Nipam/BIS gel dosimeter, each change as big as of $3^{\circ} \mathrm{C}$ or $4^{\circ} \mathrm{C}$ scan temperature led to a noticeable reduction in the response of gel dosimeter as much as $17 \%$. Abtahi et al. (29) investigated PASSAG gel dosimeter. They showed that by decreasing the scanning temperature, the sensitivity of the PASSAG gel dosimeter was increased. It was shown that for dose range of $0-10$ Gy at $15^{\circ} \mathrm{C}$ scanning temperature, the response was $1.91 \%$ and $13.49 \%$ higher than the case at room temperature $\left(22^{\circ} \mathrm{C}\right)$. Furthermore, they showed at $20^{\circ} \mathrm{C}$ scanning temperature, $1.27 \%$ and $3.7 \%$ differences in responses of gel dosimeters were obtained as compared to room temperature $\left(22^{\circ} \mathrm{C}\right)$.

By reviewing performed research in this field apparently, it seems that genipin gel dosimeter is no exception from this principle, but exception happens when readout temperature increased from $5^{\circ} \mathrm{C}$ to $10^{\circ} \mathrm{C}$. In this case, we observed an 
increase in the dose sensitivity of this gel dosimeter, as mentioned before. As a result, genipin gel dosimeter dose sensitivity amount $\left(5.72 \times 10^{-3} \mathrm{~cm}^{-1} \mathrm{~Gy}^{-1}\right)$ for dose range of $0-10 \mathrm{~Gy}$ at room temperature $\left(20^{\circ} \mathrm{C}\right)$ is comparable to other radiochromic gel dosimeters. Babic et al. (30) investigated LCV (leuco crystal violet) radiochromic gel dosimeter. The dose sensitivity of this gel dosimeter at room temperature $\left(20^{\circ} \mathrm{C}\right)$ reported $6 \times 10^{-3} \mathrm{~cm}^{-1} \mathrm{~Gy}^{-1}$.

Hence, the dose sensitivity of genipin gel dosimeter at $20^{\circ} \mathrm{C}$ readout temperature is lower than that of LCV gel dosimeter by a factor of 4.6\%. In another study, kwiatos et al. studied about NBT (nitro blue tetrazolium chloride) and tNBT (tetranitro blue tetrazolium chloride) radiochromic gel dosimeters (31). Dose sensitivities of $3.3 \times 10^{-3} \mathrm{~cm}^{-1} \mathrm{~Gy}^{-1}$ and $4.01 \times$ $10^{-3} \mathrm{~cm}^{-1} \mathrm{~Gy}^{-1}$ were reported for these gel dosimeters at room temperature $\left(20^{\circ} \mathrm{C}\right)$, respectively. Comparing the obtained results in the current study with those reported by kwiatos et al. revealed that the dose sensitivity of genipin gel dosimeter at room temperature is higher than those of NBT and tNBT gel dosimeters.

For a good fitting the goodness of fit parameter of $\mathrm{R}^{2}$ should be close to one. This value for the currently investigated gel dosimeter can be compared with that of PASSAG gel dosimeter $\left(\mathrm{R}^{2}=0.998\right)(27), \mathrm{NBT}$ and tNBT $\left(\mathrm{R}^{2}=0.9993\right.$ and $\mathrm{R}^{2}=0.9932$ respectively) (31), MAGICA $\left(R^{2}=0.9723\right)(32)$, PAGATUG $\left(R^{2}=0.9932\right)$ (22), PERSAGE $\left(\mathrm{R}^{2}=0.9958\right) \quad(33), \quad \mathrm{U}$-Nipam $\left(\mathrm{R}^{2}=0.999\right){ }^{(34)}$ and PAMPSGAT $\left(\mathrm{R}^{2}=0.998\right)$ (35). Hence, the $\mathrm{R}^{2}$ value of the genipin gel dosimeter is lower than that of PASSAG, NBT, tNBT, PAGATUG, PERSAGE, and U-Nipam gel dosimeters but higher than that of MAGICA gel dosimeter.

In a previous study (22), it was shown that the AUS sensitivity of the PAGATUG gel dosimeter was 121 times higher than that of peak sensitivity. While the current study shows that AUS sensitivity is 157.34 times higher than that of peak sensitivity for genipin gel dosimeter at room temperature $\left(20^{\circ} \mathrm{C}\right)$. It seems that an increase in AUS sensitivity for genipin gel dosimeter at lower temperatures such as $\left(50^{\circ} \mathrm{C}\right.$ and $10^{\circ} \mathrm{C}$ ) is more considerable than higher temperatures. Besides, it was shown that by increasing readout temperature and dose, the turbidity of the genipin gel could be reduced.

Results of this study are near to the findings of Davies et al. (18). They showed that the MDDs for the genipin gel dosimeter were between 0.8 Gy and 1 Gy at room temperatures investigation. Abtahi and abandansari (36) investigated the PVABAT polymer gel dosimeter. They reported that the minimum and maximum dose resolution (at 95\% confidence) are 0.089 Gy and $0.190 \mathrm{~Gy}$, respectively, for the 30-45 Gy dose range. Kipouros (37) studied about VIPAR gel dosimeter. He showed that at 25 Gy dose, this gel dosimeter demonstrated a $2 \%$ dose resolution.

Kozicki et al. (38) investigated a modified VIPAR gel dosimeter named as VIPARnd. They reported in a linear dose range dose resolution varies between 0.65-1.35 Gy. Hurley et al. (39) investigated some features of the MAGIC gel dosimeter. They reported for 0-10 Gy dose range, the dose resolution of this gel dosimeter is less than 0.5 Gy. Compared to the mentioned gel dosimeters, it seems the dose resolution of the genipin-gelatin gel dosimeter is better than VIPAR, VIPARnd, and MAGIC gel dosimeters but worse than that of PVABAT gel dosimeter.

\section{CONCLUSION}

It was cleared that the genipin gel dosimeter has a strong dependence on readout temperature. The maximum sensitivity of the genipin gel dosimeter was $35 \times 10^{-3} \mathrm{~cm}^{-1} \mathrm{~Gy}^{-1}$ which occurred_at a scanning temperature of $10^{\circ} \mathrm{C}$. In this study, a novel method was introduced for reading out the genipin gel dosimeter. It is concluded that AUS could increase the dose sensitivity of the genipin gel dosimeter by a factor of 399.71 times. Also, the dose resolution of the genipin gel dosimeter was improved than in the previous studies.

\section{Conflicts of interest: Declared none.}




\section{REFERENCES}

1. Farajollahi AR, Pak F, Horsfield M, Myabi Z (2014) The basic radiation properties of $\mathrm{N}$-isopropylacrylamide based polymer gel dosimeter. Int J Radiat Res, 12: 347-354.

2. Luciani AM, Palma A, Adorante A, Barone P, Grande S, Ranghiasci C, et al. (2006) Optical images of dose distributions in gel Fricke: dosimetric performances of the gel. Radiat Prot Dosim, 122: 455-456.

3. Farhood B, Geraily G, Abtahi SM (2019) A systematic review of clinical applications of polymer gel dosimeters in radiotherapy. Appl Radiat Isot, 143: 47-59.

4. Abtahi SM, Aghamiri SM, Khalafi H, Rahmani F (2014) An investigation into the potential applicability of gel dosimeters for dosimetry in boron neutron capture therapy. Int J Radiat Res, 12: 139-149.

5. Adinehvand K, Sardari D, Hosntalab M, Pouladian M (2017) Comparision of the effectiveness of polymer gel dosimeters (Magic and Pagatug) for organ dose calculation in brachytherapy nuclear medicine and teletherapy. Trop J Pharm Res, 16: 211-216.

6. Gambarini G, Agosteo S, Altieri S, Bortolussi S, Carrara M, Gay S, Nava E, et al. (2007) Dose distributions in phantoms irradiated in thermal columns of two different nuclear reactors. Radiat Prot Dosim, 126: 640-644.

7. Colnot J, Hue TC, Gshwind R, Clairand I (2018) Characterisation of two new radiochromic gel dosimeters TruView ${ }^{\text {TM }}$ and Clearview ${ }^{\mathrm{TM}}$ in combination with vista ${ }^{\mathrm{TM}}$ optical CT scanner: a feasibility study. Europ J Med Phys, 52: 154164.

8. Allahverdi-Pourfallah $\mathrm{T}$, Allahverdi M, Riahi N, Zahmatkesh $\mathrm{MH}$ (2009) Verifying the accuracy of dose distribution in Gamma Knife unit in presence of inhomogeneities using pagat polymer gel dosimeter and $\mathrm{MC}$ simulation. Int $J$ Radiat Res, 7: 49-56.

9. Michael S and Erik JL (2017) Stereotactic radiosurgery delivery verification tetrazolium salt-based gel as a dosimeter Can J Phys, 95: 725-730.

10. Yao CH, Liu BS, Chang CJ, Shu SH, Chen YS (2004) Preparation of networks of gelatin and genipin as degradable biomaterial. Mat Chem Phys, 83: 204-208.

11. Lee SW, Lim JM, Bhoo SH, Paik YS, Hahn TR (2003) Colorimetric determination of amino acids using genipin from gardenia jasminoides. Analytica Chemica Acta, 480 267-274.

12. Jordan K (2008) Zero diffusion radiochromic genipingelatin dosimeter. Int J Med Phys Res, 35: 3413-3418.

13. Babic S, Battista J, Jordan K (2009) Three-dimensional dosimetry of small megavoltage radiation fields using radiochromic gels and optical CT scanning. Phys Med Biol, 54: N22.

14. Marrale M, Collura G, Gallo S, Nici S, Tranchina L, Abbate BF, Marineo S, Caracappa S, Errico F (2017) Analysis of spatial diffusion of ferric ions in PVA-GTA gel dosimeters through magnetic resonance imaging. Nucl Instrum Meth Phys Res A, 396: 50-55.

15. Davies JB and Baldock C (2008) Sensitivity and stability of

Int. J. Radiat. Res., Vol. 19 No. 3, July 2021 the Fricke-gelatin-xylenol orange gel dosimeter. Radiat Phys Chem, 77: 690-696.

16. Gorjiara T, Hill R, Kuncic Z, Bosi S \& Baldock C (2010) An evaluation of genipin gel as a water equivalent dosimeter for megavoltage electron beams and kilovoltage X-ray beams. Journal of Physics: Conference Series, 250: 012036.

17. Gorjiara T, Hill R, Kuncic Z, Bosi S, Davies JB, Baldock C (2011) Radiological characterization and water equivalency of genipin gel for $\mathrm{x}$-ray and electron beam dosimetry. Phys Med Biol, 56: N15.

18. Al-jarrah AM, Rahman AA, Shahrim I, Razak NNA, Ababneh B, Taghizadeh E (2016) Effect of inorganic salts and glucose additives on dose-response, melting point and mass density of genipin gel dosimeters. Europ J Med Phys, 32: 36-41.

19. Davies JB, Baldock C, Bossi SG (2012) A genipin-gelatin gel dosimeter for radiation processing. Radiat Phys Chem, 81: 1263-1265.

20. Davies JB, Baldock C, Bossi SG (2013) Dosimetry aspects of a non-diffusing genipin-gelatin gel. Radiat Phys Chem, 83: 19-27.

21. De Deene Y, Vergote K, Claeys C, Wagter C (2006) The fundamental radiation properties of normoxic polymer gel dosimeters: a comparision between a methacrylic acid based gel and acrylamide based gels. Phys Med Biol, 51: N3.

22. Abtahi SM, Aghamiri M, Khalafi H (2014) Optical and MRI investigations of an optimized acrylamide-based polymer gel dosimeter.J Radioanal_Nucl Chem, 300: 287-301.

23. Joaquim $P$ and Marques DS (2007) Applied Statistics Using SPSS, STATISTICA, MATLAB and R, (New York: Springer) $2^{\text {th }}$ Edn.

24. Baldock C, Lepage M, Back SA, Murr PJ, Jayasekera PM, Porter D, Kron T (2001) Dose resolution in radiotherapy gel dosimetry: effect of echo spacing in MRI pulse sequence. Phys Med Biol, 46: N22.

25. De Deene $Y$ (2004) Fundamentals of MRI measurements for gel dosimetry. Journal of Physics: Conference Series, 3: 87-114.

26. Rink A, David F, Varma S, Vitkin A, Jaffary D (2008) Temperature and hydration effects on absorbance spectra and radiation sensitivity of a radiochromic medium. Int J Med Phys Res, 35: 4545-4555.

27. Pavoni JF and Baffa O (2012) An evaluation of dosimetric characteristics of MAGIC gel modified by adding formaldehyde (MAGIC-f). Radiat Meas, 4: 1074-1082.

28. Senden R, Jean PD, Mcauley KB, Schreiner U (2006) Polymer gel dosimeters with reduced toxicity: a preliminary investigation of the NMR and optical doseresponse using different monomers. Phys Med Biol, 51: 3301-14.

29. Farhood B, Abtahi SM, Geraily G, Gorbani M, Mahdavi S, Zahmatkesh MH (2018) Dosimetric characteristics of PASSAG as a new polymer gel dosimeter with negligible toxicity. Radiat Phys Chem, 147: 91-100.

30. Babic S, Battista J, Jordan K (2009) Radiochromic leuco dye micelle hydrogels:Il. Low diffusion rate leuco crystal violet gel. Phys Med Biol, 54: 22-41. 


\section{Bahrami et al. / Scan temperature effect on genipin gel response}

31. Kwiatos K, Maras P, Kadlubowski S, Stempien Z, Dudeck M, Kozicki M (2018) Tetrazolium salts-Pluronic F-127 gels for 3D radiotherapy dosimetry. Phys Med Biol, 63: 9-27.

32. Khadem-Abolfazli M, Mahdavi M, Mahdavi SRM, Ataei GH (2013) Dose enhancement effect of gold nanoparticles on MAGICA polymer gel in mega voltage radiation therapy. Int J Radiat Res, 11: 55-61.

33. Iqbal K, Ibbott S, Lafratta R, Gifford K (2018) Dosimetric feasibility of an anthropomorphic three -dimensional PRESAGE $^{\circledR}$ dosimeter for verification of single entry hybrid catheter accelerated partial breast brachytherapy. J Radiotherapy in Practice, 20: 37-54.

34. Abtahi SM, Anaraki V, Farhood B, Ejtemai-fard M (2018) A novel method for increasing the sensitivity of NIPAM polymer gel dosimeter. Radiat Phys Chem, 153: 35-43.

35. Abtahi SM and Pourghanbari M (2018) A new less toxic polymer gel dosimeter: Radiological characteristics and dosimetry properties. Europ J Med Phys, 53: 137-144.

36. Abtahi SM and Abandansari HS (2017) Polymer gel dosimeters with PVA-GA matrix. Austral Phys Engin Scien Med, 40: 651-658.

37. Kipouros $P$, Pppas E, Baras $P$, Hatsipanayoti D, Karaiskos $P$, Sandilos P, Seimenies I (2001) Wide dynamic dose range of VIPAR polymer gel dosimetry. Phys Med Biol, 46: N8.

38. Kozicki M, Jaczak M, Maras P, Dudeck M, Clapa M (2017) On the development of a VIPARnd radiotherapy 3D polymer gel dosimeter. Phys Med Biol, 62: 986-1008.

39. Hurley C, Lucas C, Pedrazini G, Baldock C (2006) High resolution gel dosimetry of a HDR brachytherapy source using normoxic polymer gel dosimeters:preliminary study. NuCl Instrum Meth Phys Res, 565:801-816. 